\title{
Geoelectrical Survey for Engineering Investigation
}

\author{
A. H. A Teh Saufia, Rosli Saad, M.M. Nordiana, I.N. Azwin, Andy A. Bery, \\ Noer El Hidayah Ismail, Nisa’ Ali, Mark Jinmin, Y.C. Kiu, S.L. Ragu Ragava R. \\ Geophysics Section, School of Physics, Universiti Sains Malaysia, Penang, Malaysia \\ Email: teh.saufia@gmail.com
}

Received 2013

\begin{abstract}
Water seepage erosion has been and remains one of the major engineering problems. However, most engineers will much depend on borehole data and soil test for designing and problem detection. By considering of the cost and destructive method, selection of geoelectrical prospecting would be appropriate. Therefore, two electrical geophysical surveys were carried out in Sekolah Menengah Kebangsaan Dato' Haji Mohd Nor, Gelugor, Pulau Pinang to map the presence of the unknown underground water sources (saturated zones) and its movement. With the total of seven resistivity lines parallel to each other and self potential (SP) with $5 \mathrm{~m} \times 5 \mathrm{~m}$ gridding survey were successfully done. The resistivity result from line 1 (R1) to line 6 (R6) shows the subsurface consist of saturated zones with range between $3 \mathrm{~m}$ up to $10 \mathrm{~m}$ depth, before it reaches the R7 which is believed as the accumulation zone. Meanwhile, as for SP result it shows the water flow from higher value (north-east) towards the lower value which is mostly at the south area. In conclusion, geoelectrical survey could assist in detecting and solving engineering problems as it proven by the result from each method.
\end{abstract}

Keywords: Geoelectrical; 2D Resistivity; Self Potential; Engineering

\section{Introduction}

Geoelectrical survey is commonly known in environmental or engineering prospecting. Geophysical studies which provide nondestructive methods have recently been employed to reduce cost and numerous problems [1]. With advantages of non-invasive, low cost and fast, geophysical method always become as a primary solution in various exploration. One of the common problems engineering field would be soil erosion due to water movement either on the surface or beneath the surface. In general, soil erosion can be defined as one form of soil degradation along with soil compaction, low organic matter, loss of soil structure, poor internal drainage, salinization, and soil acidity problems. Due to the changes of the properties and behavior of the soil, therefore, it can influence both construction operations and the performance of completed construction [2]. Hence, geoelectrical survey would be appropariate tool as it is most likely measured the changes of resistivity (or conductivity) which is one of the most important physical properties of the rock. In this study, the overflowing of unknown water sources at the retaining wall has created a tremendous interest. It is because it could be the factor of water seepage beneath the subsurface which could leads to landslide or soil erosion. Hence, this study is aimed to locate the unknown water source and its movement.

\section{Study Area}

The survey was conducted at Gelugor, Penang within SMK Dato Haji Mohd Nor Ahmad's compound. The survey was done on the school's field which was recently undergoing a piping reconstruction beneath it. During monitoring and observation session at this area, it predictably was facing several engineering problems. With heavy and unstoppable flow of water through retaining wall which can be clearly seen from the outside of the school as well as few pools or water puddles on the field ground, it strengthen the fact that currently experience water seepage problems. Following Figure 1 is the location of the study area with survey lines.

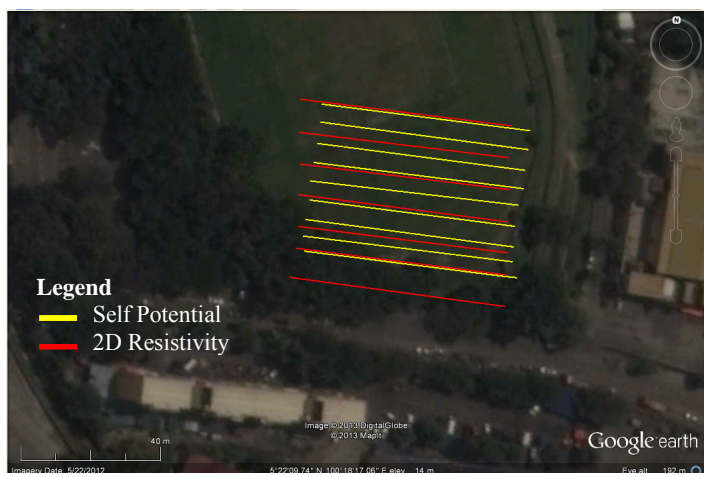

Figure 1. Location of the study area. 


\section{Methodology}

Electrical prospecting uses a large variety of techniques based on some different electrical property or characteristic of materials in the Earth. In this study, two geoelectrical methods were applied. Each of these methods has its own advantages and disadvantages. Further explanations can be seen in the following topics:

\subsection{D Resistivity}

Resistivity is a property possessed by all materials [3]. The 2D electrical resistivity method utilizes the knowledge that in soil and rock materials, the resistivity values differ sufficiently to permit the property to be used for identification purposes. A low resistivity indicates a material that readily allows the movement of electrical charge. In earth material, resistivity decreases with increasing water content and increasing salt concentration. Resistivity method is designed to yield information on formations or bodies having anomalous electric conductivity. Few electrodes setup along a straight line will attach to multi core cable. The purpose of resistivity surveys is to map the subsurface resistivity distribution by making apparent resistivity measurements on the ground surface. Apparent resistivity measurements are made by injecting current into the ground through two current electrodes and measuring the resulting voltage difference between two potential electrodes. There are seven survey lines were conducted with $60 \mathrm{~m}$ of total length of each lines. All these lines were using pole-dipole array as it relevant to the objective of this study which requires good in horizontal and vertical resolution.

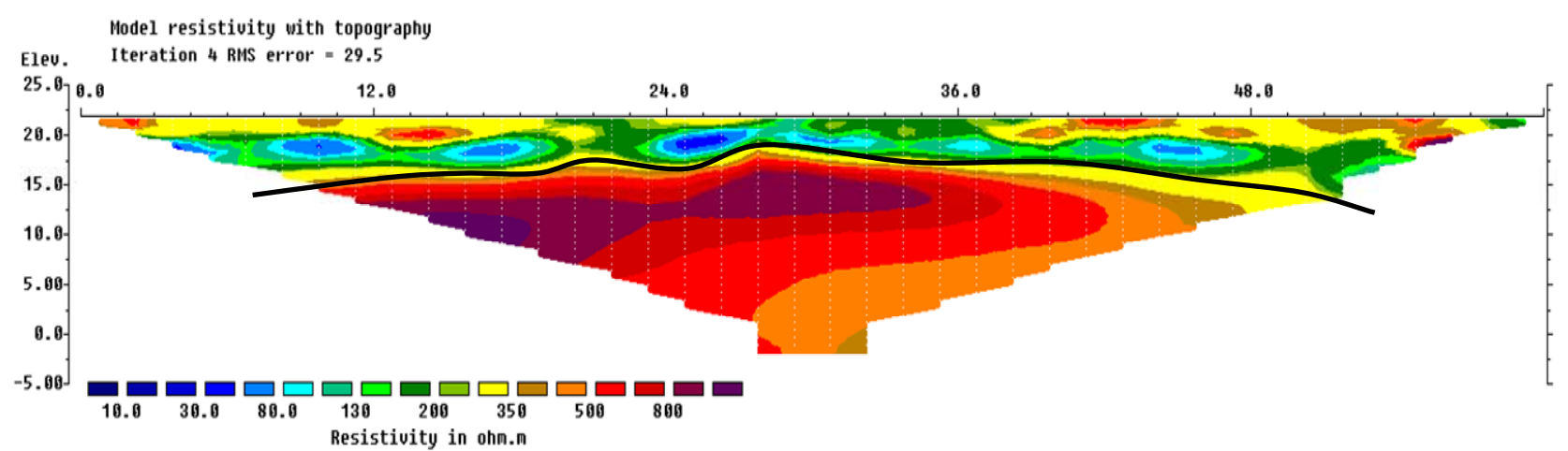

R1

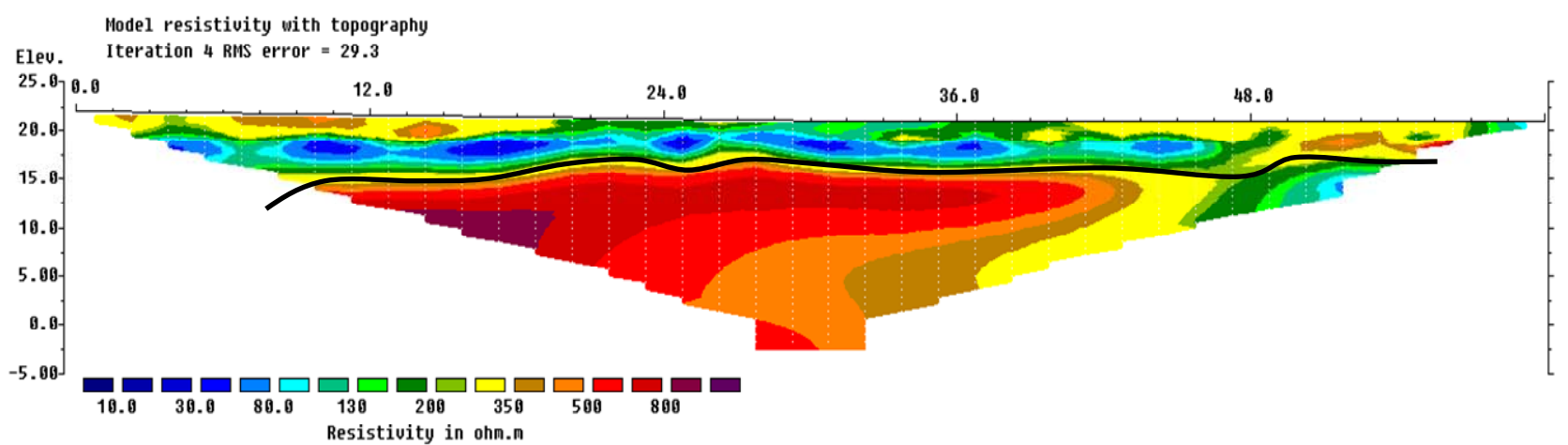

R2

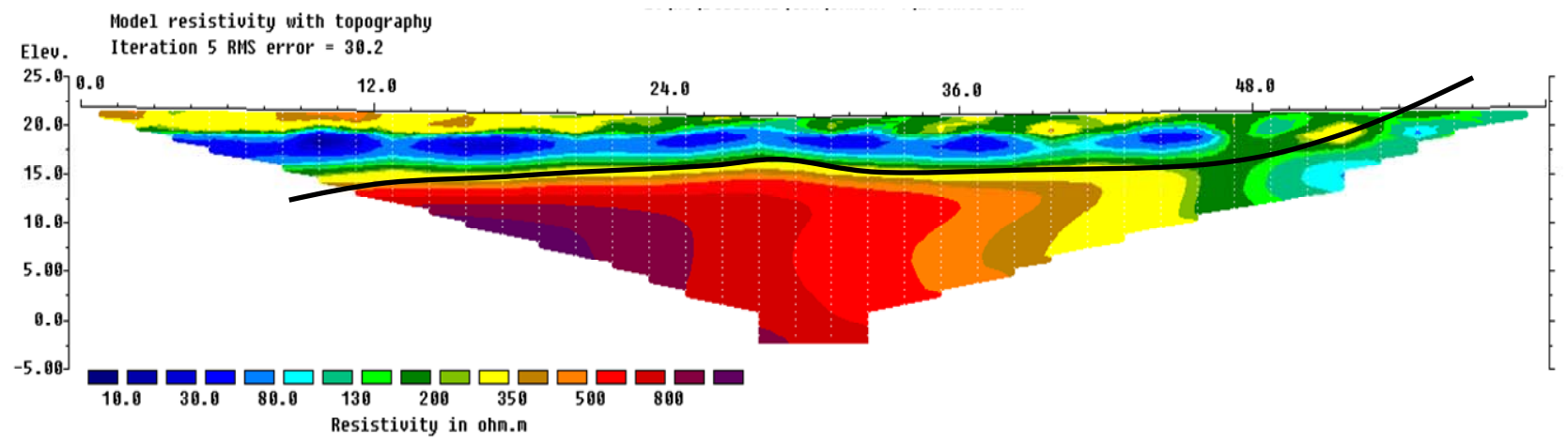




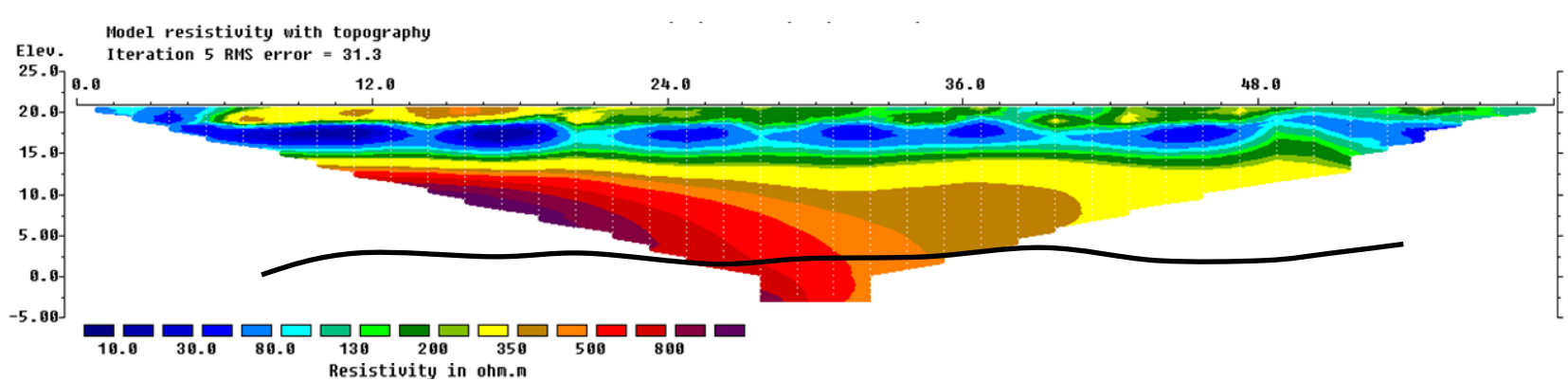

R4

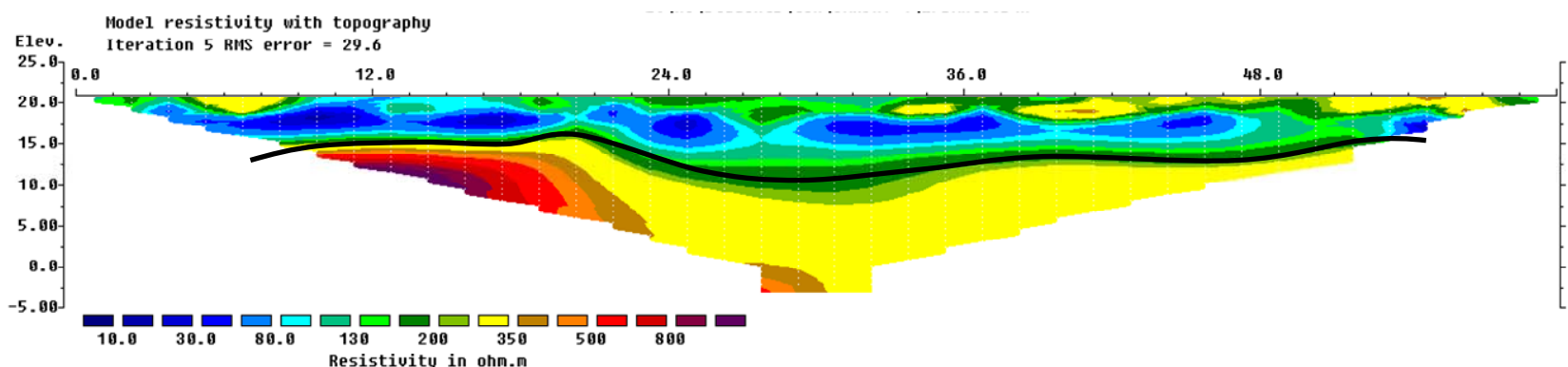

R5

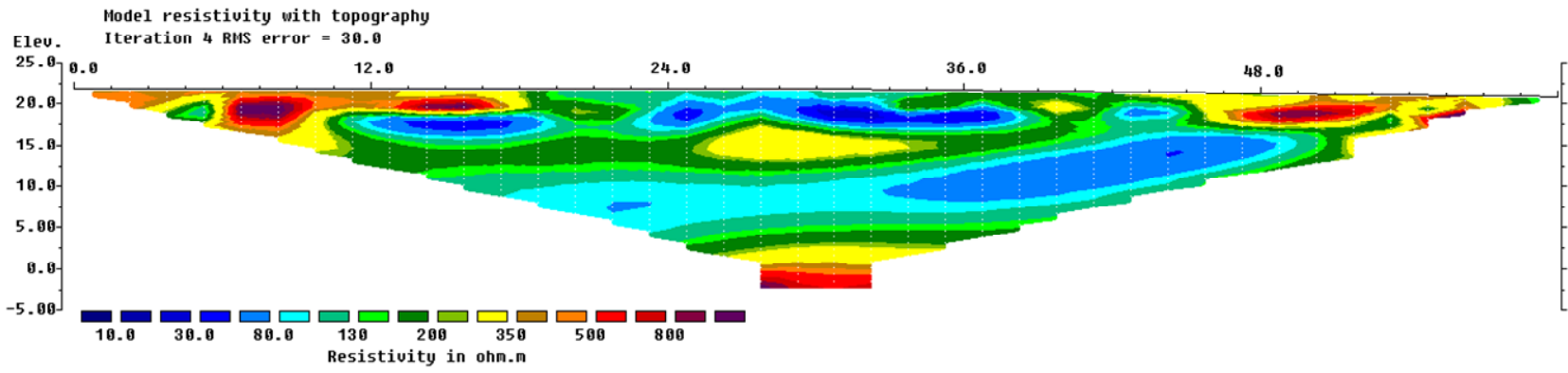

R6

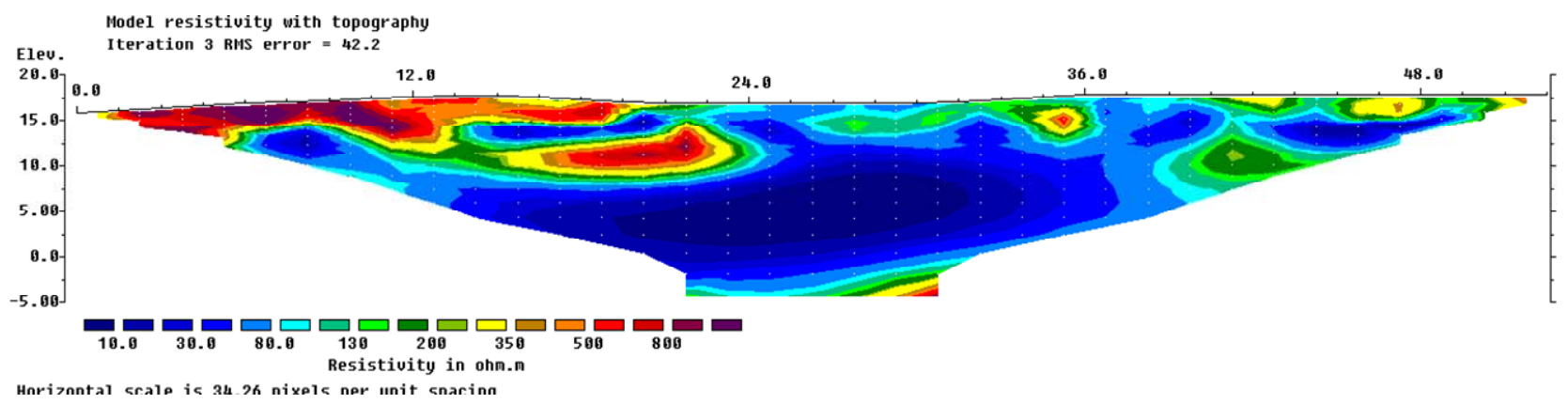

R7

Figure 2. Resistivity result (R1 to R7).

\subsection{Self Potential}

SP signals are electrical fields passively measured at the ground surface of the Earth using non-polarizing electrodes [4]. Self potential surveys measure the difference in potential between any two points on the ground produced by small, naturally produced currents that occur beneath the Earth's surface. This method is non-destructive, fast, inexpensive, and very simple to be applying in the field [5]. Small potentials of the order of a few milivolts are produced by two electrolytic solutions of differing concentrations that are in direct contact and by the flow of electrolytic fluid through porous materials (streaming potential). As for self potential, the orientation of the survey is slightly different which done using gridding survey was. With distance between porous pots is $5 \mathrm{~m}$ spacing, contour space of $60 \mathrm{~m} \times 40 \mathrm{~m}$ was obtained. 


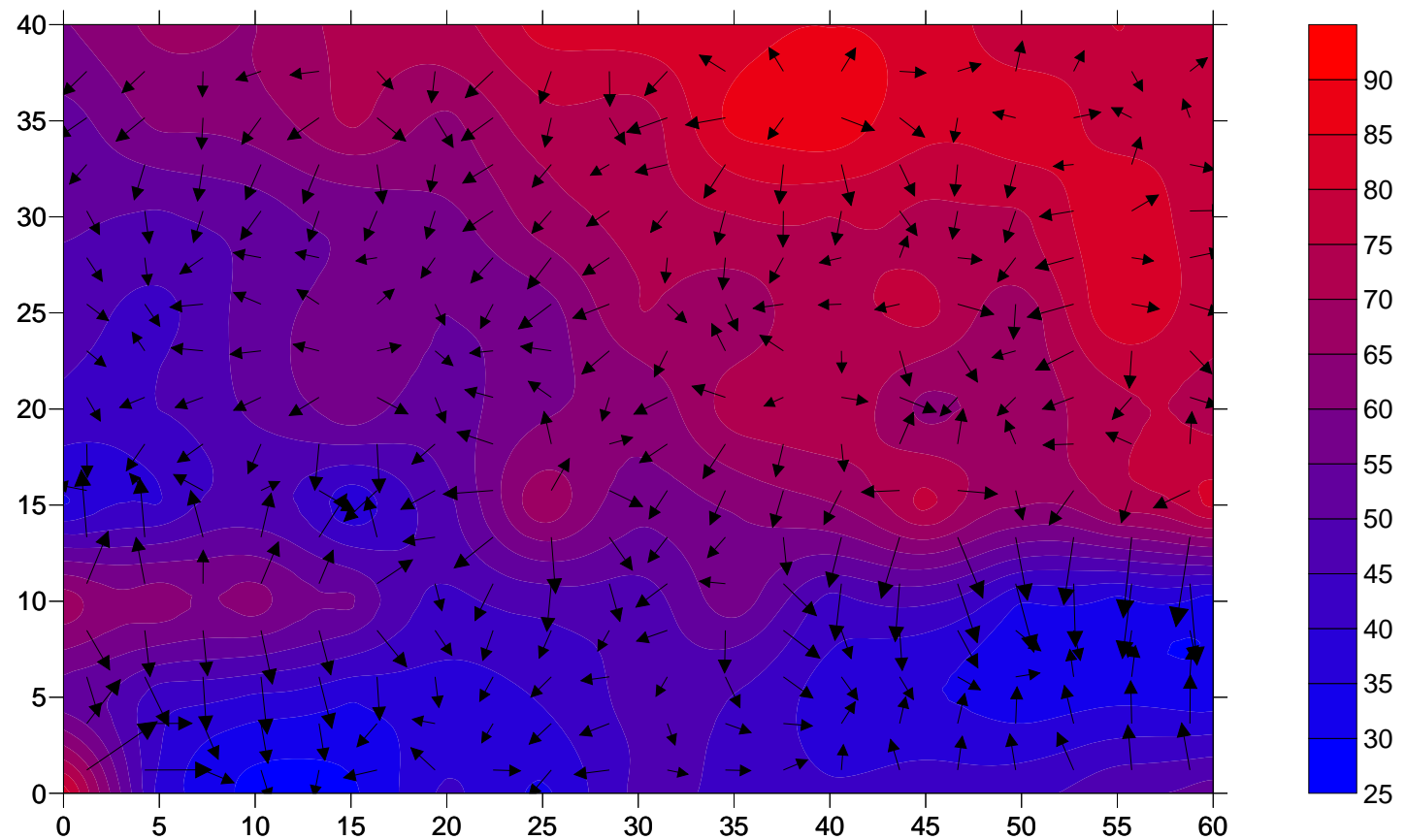

Figure 3. SP result.

\section{Results \& Discussion}

Based on 2D resistivity results, it shows that this area can be divided into two major resistivity zones. The first zone would be at the top with resistivity value of $<$ $80 \Omega \mathrm{m}$ and thickness varies $3 \mathrm{~m}$ to $10 \mathrm{~m}$ depth. Therefore, it was classified as saturated zone. A higher value of resistivity layers which is $>80 \Omega \mathrm{m}$ with depth range between $10 \mathrm{~m}$ to $35 \mathrm{~m}$ classified as dry and compacted zones. However it differs for R7 as it is believed to be the accumulation zone for the water before it reaches the retaining wall. As from, the SP result, it can be clearly seen from the arrow that the flow comes from the higher value (red) to lower value (blue). As in this case, the lower value indicates infiltration zone for the subsurface. These two methods correlate well with each other.

\section{Conclusions}

In conclusion, the aim of the research was successfully obtained. The saturated zone can be clearly defined. Together with the flow of the water obtained from SP result, really help in determining the source. The worrisome matter regarding water seepage is the occurrence of soil erosion which could lead major engineering problems if non-active action taken.

\section{Acknowledgements}

The authors would like to thank to Principal of SMK Hj. Mohd Nor Ahmad for his cooperation in giving permission to do this research project in school compound. Not forgotten, to all technical staffs of Geophysics Section, Universiti Sains Malaysia and fellow colleagues for their tremendous help in the lab and during the data acquisition.

\section{REFERENCES}

[1] S. Komatina and Z. Timotijevic, "Some Case Studies of Geophysical Exploration of Archaeolgical Sites in Yugoslavia," Journal of Applied Geophysics, Vol. 41, No. 2-3, 1999, pp. 205-213. doi:10.1016/S0926-9851(99)00002-6

[2] D. F. McCarthy, "Essentials of Soil Mechanics and Foundations: Basic Geotechnics," 7th Edition, Prentice Hall, 2007.

[3] C. Venkatramaiah, "Geotechnical Engineering," NewAge International (P) Ltd Publishers, Delhi, 2006.

[4] A. A. Ogilvy, "Studies of Undergroundwater Movement," Geol. Surv. Can. Rep., Vol. 26, 1967, pp. 540-543

[5] A. Revil, V. Naudet and J. D. Meunier, "The Hydroelectric Problem of Porous Rocks: Inversion of the Position of the Water Table from Self-Potential Data," Geophysics Journal International, Vol. 159, 2004, pp. 435-444. doi:10.1111/j.1365-246X.2004.02422.X 